\title{
Molecular basis for phenotypic heterogeneity in galactosaemia: prediction of clinical phenotype from genotype in Japanese patients
}

\author{
Hidetetsu Hirokawa ${ }^{1}$, Yoshiyuki Okano ${ }^{1}$, Minoru Asada $^{1}$, Akie Fujimoto ${ }^{2}$, \\ Itsujin Suyama ${ }^{3}$ and Gen Isshiki ${ }^{1}$ \\ ${ }^{1}$ Department of Pediatrics, Osaka City University Medical School, Osaka \\ ${ }^{2}$ Osaka City Environment and Public Health Association, Osaka \\ ${ }^{3}$ Osaka Municipal Rehabilitation Center for the Disabled, Osaka, Japan
}

\begin{abstract}
We identified 14 mutations in 15 Japanese subjects from 13 families with galactose-1-phosphate uridyltransferase (GALT) deficiency using denaturing gradient gel electrophoresis (DGGE) and direct sequence analysis. These mutations accounted for $22(96 \%)$ of 23 mutant alleles in 15 Japanese subjects. The mutational spectrum included nine missense mutations (M142V, G179D, A199T, R231H, W249R, N314D, P325L, R333Q, and R333W), two deletions (L275fsdelT and Q317fsdelC), a nonsense mutation (W249X), and two splicing mutations (V85-N97fsdel38bp and IVS4nt ${ }^{+} 1$ ). Ten of the 14 mutations have not been reported in Caucasians. Differences in frequency and spectrum of GALT mutations suggest that the mutations may have occurred after racial divergence of Caucasians and Asians. The Duarte variant in Japanese was associated with the N314D mutation, g.1105G $>\mathrm{C}$, g.1323G $>\mathrm{A}$, and g.1391G > A (SacI -) polymorphisms, as in Caucasians. The Duarte variant may have occurred before racial divergence, and was an ancient mutation. In vitro GALT activities of nine missense mutations were determined by a COS cell expression system, and indicated between $1.3 \%$ and $35 \%$ of wild-type control. Patients with R333Q (29\% in vitro GALT activity) or A199T (35\%) showed mild clinical phenotypes, ie no ovarian failure or neurological deterioration. Genotype determination is useful for predicting biochemical and clinical phenotypes in classic galactosaemia, and can be of further help in managing patients with this disorder.
\end{abstract}

Keywords: galactosaemia; galactose-1-phosphate uridyltransferase; mutation; Duarte variant; Los Angels variant; deletion; splicing; phenotype; genotype

Correspondence: Yoshiyuki Okano MD, Department of Pediatrics, Osaka City University Medical School, 1-4-3 Asahimachi, Abeno-ku, Osaka 545-8585, Japan. Tel: 81666453816 ; Fax: 81666368737 ;

E-mail: okano@med.osaka-cu.ac.jp

Received 1 February 1999; revised 10 May 1999; accepted 18

May 1999 


\section{Introduction}

Classic galactosaemia is an autosomal recessive genetic disorder due to a deficiency of galactose-1-phosphate uridyltransferase (GALT). The incidence of classic galactosaemia in Caucasians is 1:40000-60000, ${ }^{1}$ compared with 1:1000000 in the Japanese. ${ }^{2}$ This disease causes neonatal jaundice, cataracts, hepatomegaly, failure to thrive, and even neonatal death, if the patient is not rigorously maintained on a lactose-free diet. Early diagnosis and treatment through newborn mass screening have been performed in Japan since 1977. Despite the favourable results of early diagnosis and galactoserestricted diet, late-onset symptoms, such as ovarian failure and neurological deterioration, have been reported, ${ }^{3,4}$ the pathophysiological mechanisms of which remain unknown.

Over 100 distinct mutations have been reported, mainly in the Caucasian population, since the first report of mutations in GALT patients in $1991^{5}$ (Tyfield GALT database, available at: http:/www.alspac1.ich.bris.ac.uk/galtdb/ accessed 7 July 1998). Molecular genetic analysis can provide new information on impaired GALT function and enable prediction of the outcome in affected patients. The Q188R mutation is the most prevalent among patients with GALT deficiency in Caucasians, accounting for over $60 \%$ of all galactosaemic alleles, and is related to classic galactosaemia with neurologic symptoms and ovarian failure. $^{6-8}$ T138M, T350A, R259W, A330V mutations have been reported to be associated with mild biochemical phenotypes. ${ }^{9,10}$ In molecular analysis of the variants, the N314D mutation and g.1391G $>$ A $\left(\mathrm{SacI}^{-}\right)$polymorphism were clearly associated with the Duarte variant with $50 \%$ of normal GALT activity. ${ }^{11-13}$ The N314D mutation and $\mathrm{L} 218 \mathrm{~L}$ polymorphism (g.1721C $>\mathrm{T}$ in exon 7) have been associated with the Los Angeles variant with GALT activity above the normal range. ${ }^{14}$ The role of N314D mutation for the Duarte and Los Angeles variants is still unclear.

In a previous study, we reported two mutations of R213H and V85-N97fsdel38bp in two Japanese patients with typical classic galactosaemia phenotype. ${ }^{15}$ In order to investigate the molecular basis for phenotypic heterogeneity in galactosaemia, we analysed mutations in Japanese subjects with GALT deficiency using denaturing gradient gel electrophoresis (DGGE) and direct sequencing, and examined the in vitro GALT activity of mutant GALT cDNA constructs using a COS cell expression system.

\section{Materials and Methods}

Patients

The biochemical phenotype and genotype of the 15 Japanese subjects studied are presented in Table 1. Patients 1A, 1B, 2, and 3 were diagnosed with GALT deficiency before the mass screening of newborns had begun in Japan. Patients 2 and 3 exhibited typical symptoms of classic galactosaemia and were diagnosed with reduced levels of GALT activity in RBC, as reported earlier. ${ }^{15}$ Patients 4 to 8 were detected by mass screening of newborns and were diagnosed as GALT deficiency at the respective institutions, and were started on a galactose-restricted diet immediately after diagnosis. Their psychomotor development was normal. Patients 9 to 13 exhibited weak fluorescence in the Beutler screening test and mild elevation of galactose concentration in the Paigen screening test. They were diagnosed as heterozygous carriers based on GALT activity in their RBCs.

Patients $1 \mathrm{~A}, \mathrm{~B}$, and 4 were female and had passed adolescence with mild clinical phenotypes. Patient $1 \mathrm{~A}$ had feeding failure, insufficient weight gain, hepatomegaly, cataract, and a serum galactose concentration of $6.7 \mathrm{~mol} / \mathrm{L}$. She was diagnosed with GALT deficiency two months after birth. She started on a galactose-restricted diet and continued the strict dietary treatment. Her IQ was 84 at the age of 6 . She had a regular menarche and later became pregnant, and gave birth to a normal child. No marked ovarian failure or neurological deterioration has been found. Patient $1 \mathrm{~B}$, the younger sister of patient $1 \mathrm{~A}$, was found to have hyperbilirubinaemia 3 days after birth. She started on a galactose-restricted diet 12 days after birth, and continued the strict dietary treatment. Psychomotor development was normal and she had menarche at age 13. ${ }^{16}$ Patient 4 was diagnosed by mass screening of newborns, and had continued the strict galactose-restricted diet. She had menarche at age 15, and did not exhibit

Table 1 Biochemical phenotypes and genotypes of Japanese subjects with GALT deficiency

\begin{tabular}{lcl}
\hline Subjects & $\begin{array}{l}\text { GALT } \\
\text { activity }(\%)\end{array}$ & Genotype \\
\hline 1A & $2.5^{\mathrm{a}}$ & A199T/L275fsdelT \\
$1 \mathrm{~B}$ & $2.5^{\mathrm{a}}$ & A199T/L275fsdelT \\
2 & $<1$ & R231H/R231H \\
3 & $<1$ & V85-N97fsdel38bp/ \\
4 & $5^{\mathrm{b}}$ & V85-N97fsdel38bp \\
5 & $<1^{\mathrm{b}}$ & W249X/R333Q \\
$6 \mathrm{~A}$ & $19^{\mathrm{b}}$ & N3142V/R333W \\
$6 \mathrm{~B}$ & $1^{\mathrm{b}}$ & P325L/P325L \\
7 & 2 & IVS4nt+1/W249X \\
8 & $7^{\mathrm{b}}$ & W249R/unknown \\
9 & 32 & N314D/Q317fsdelC \\
10 & 62 & G179D/Normal \\
11 & 48 & P325L/Normal \\
12 & 40 & V85-N97fsdel38bp/Normal \\
13 & 53 & V85-N97fsdel38bp/Normal \\
\hline
\end{tabular}

aALT activity was measured in lymphoblasts transformed with Epstein-Barr virus;

${ }^{\mathrm{b}}$ GALT activity was measured in RBCs at each institution to detect patients with GALT deficiency. 
hypergonadotrophic hypogonadic reaction on LH-RH loading test at age 16. Her psychomotor development was normal at age $16 .{ }^{17}$ Informed consent for gene analysis was obtained from all the subjects or their families.

\section{Denaturing Gradient Gel Electrophoresis}

Genomic DNA was prepared from white blood cells or lymphoblasts transformed with Epstein-Barr virus. The 11 exons and flanking intronic regions in the GALT gene were amplified by polymerase chain reaction (PCR) with GC-clamped sense primers and anti-sense primers (Table 2). Reaction mixtures obtained $0.5-1.0 \mu \mathrm{g}$ of genomic DNA, $2 \mathrm{~mm}$ of each dNTP, $50 \mathrm{~mm} \mathrm{KCl}, 100 \mathrm{~mm}$ Tris-HCl (pH 8.3), $15 \mathrm{~mm} \mathrm{MgCl}_{2}, 0.1 \%$ gelatin, $100 \mathrm{ng}$ GC-clamped primer, $50 \mathrm{ng}$ of anti-sense primer, and Amplitaq (Perkin-Elmer, Norwalk, CT, USA). Thirty-five PCR cycles were performed using the following thermal profile: $94^{\circ} \mathrm{C}$ for $30 \mathrm{~s}, 50^{\circ} \mathrm{C}$ for $60 \mathrm{~s}$, and $72^{\circ} \mathrm{C}$ for $60 \mathrm{~s}$. The mixture was finally incubated at $72^{\circ} \mathrm{C}$ for $5 \mathrm{~min}$ in a thermal sequencer (TSR-300, Iwaki, Funaba Shi, Japan). GC-clamped PCR products $(20 \mu \mathrm{l})$ were loaded on to a $6 \%$ polyacrylamide gel containing a linear gradient of urea and formamide ranging from 20 to $80 \%{ }^{18}$ Electrophoresis was performed at $160 \mathrm{~V}$ for $7 \mathrm{~h}$ in a $61^{\circ} \mathrm{C}$ TAE buffer $(0.04 \mathrm{M}$ Tris acetate, $1 \mathrm{~mm}$ EDTA, $\mathrm{pH} 8.0)$ using denaturing gradient gel electrophoresis apparatus (CBS Scientific, Solana Beach, CA, USA).

\section{Genomic DNA Sequencing}

The 11 exons were divided into nine regions, combining exons 3 and 4 , and exons 5 and 6 . Each region was amplified from genomic DNA by PCR with biotinylated sense primer and anti-sense primer using the following thermal profile: $94^{\circ} \mathrm{C}$ for $60 \mathrm{~s}, 54^{\circ} \mathrm{C}$ for $120 \mathrm{~s}$, and $72^{\circ} \mathrm{C}$ for $180 \mathrm{~s}$ in a thermal sequencer. The amplified products were purified to a single-strand DNA using magnetic beads coated with streptavidin M280 (Dynal, Oslo, Norway). The single-strand DNA was sequenced directly with anti-sense primers for GALT sequence using a Sequenase ver. 2.0 kit (Amersham, Buckinghamshire, England).

Detection of $g .1105 G>C, g .1323 G>A, g .1391 G>A$, and g.1721C $>T$ Polymorphisms

Detection of g.1105G $>$ C polymorphism was performed by amplifying intron 4 region with sense-biotinylated primer 5'-AGCAAAGTCTGCTCGAG-GAGTC-3' and anti-sense primer 5'-ACCCAGCTCCTCTGTGACTGA-3'. The PCR products were purified to a single-strand DNA and were sequenced with sense primer 5'-AACCAGAGTTGGAGACTCAG-3'. Detection of g.1391G $>$ A polymorphism $\left(\mathrm{SacI}^{-}\right)$was performed by amplifying the intron 5 region with sense primer 5'-TCAGTCACAGAGGAGCTGGGTG-3' and anti-sense primer 5'-AATCCTGTTCCCATGTCCACA3'. The PCR products (325 bp) were digested with SacI (New England Biolabs, Beverly, MA, USA), and the $\mathrm{SacI}^{+}$chromosome exhibited two fragments of 149 and $176 \mathrm{bp}$. The detection of $\mathrm{g} .1323 \mathrm{G}>\mathrm{A}$ polymorphism was performed by digesting PCR products (325 bp) of the intron 5 region with DdeI (New England Biolabs). The $D d e \mathrm{I}^{+}$chromosome exhibited four fragments of $6,32,101$, and $186 \mathrm{bp}$, instead of three fragments of 6,32 , and $287 \mathrm{bp}$ of DdeI. Detection of g.1721C > T polymorphism (L218L, $\mathrm{Mse}^{+}$) in exon 7 was performed by digesting PCR products of exon 7 ( $262 \mathrm{bp}$ ) with MseI (New England Biolabs). The g.1721C > T chromosome $\left(\mathrm{Mse}^{+}\right)$exhibited two fragments of 138 and $124 \mathrm{bp}$. The products of digestion were analysed by electrophoresis by a $3 \%$ agarose gel.

\section{Expression Analysis}

The wild-type full-length human GALT cDNA fragment from pJR16 GALT ${ }^{5,19}$ was subcloned into the eukaryotic expression vector pcDNA 3 (Invitrogen, San Diego, CA, USA). Mutant GALT cDNA was synthesised by specific base substitution into pcDNA 3 GALT using site-directed mutagenesis. Mutant and wild-type pcDNA 3 GALT were introduced into monkey kidney COS cells by electroporation with a Gene Pulser apparatus (Bio-Rad, Hercules, CA, USA) as described previously. ${ }^{20}$ The cells were harvested after $72 \mathrm{~h}$ of culture, and GALT mRNA and GALT activity in cellular extracts were determined. GALT mRNA levels in cell extracts were determined by dot-blot hybridisation for serially diluted total-RNA samples with a GALT cDNA probe labelled with $\left[\alpha-{ }^{32} \mathrm{P}\right] \mathrm{dCTP}$ (DuPont-NEN, Boston, MA, USA) using the Megaprime DNA labelling system (Amersham). GALT activity of each mutant construct was determined as described previously. ${ }^{15}$

\section{Results}

\section{DGGE Analysis and Genomic DNA Direct Sequencing}

In this study, we performed DGGE analysis and direct sequencing on a total of 23 mutant alleles from nine

Table 2 PCR primers for DGGE and direct sequencing

\begin{tabular}{lll}
\hline Exon & Sense primer $\left(5^{\prime}->3^{\prime}\right)$ & Anti-sense primer $\left(5^{\prime}->3^{\prime}\right)$ \\
\hline Exon 1 & (GC) ACGGCCCTGCAGATTTTCCA & TGAGCGTTCCAACCTTCGGA \\
Exon 2 & (GC) CCAGGAGAGAGGGAGCTAGA & AAGGAGGTTCACTATCCTGT \\
Exon 3 & (GC) CACCAGGTAACTGGTGGTAT & GCAGAACTCCCTCAAGAGGT \\
Exon 4 & (GC) CAGAGAGTGATACTCCTTTA & AACCCCAATGCTGAGTCTCC \\
Exon 5 & (GC) ACAGCCAAGCCCTACCTCTC & CCAGAACCAAAGCTTCATCA \\
Exon 6 & (GC) ACTTGGTGTCTTTTGCTAA & AAGAACAGGCAGGTCCTTTA \\
Exon 7 & (GC) CTTGGAGGTAAAGGACCTGC & GTTCACCTCTAGCTTTCTCC \\
Exon 8 & (GC) TGACCACACTCCGGCTCCTA & GCTGACCCTACTGGGAGCAA \\
Exon 9 & (GC) TTGCTCCCAGTAGGGTCAGC & CAGCATCTCTACTCTGGCCA \\
Exon 10 & (GC) GTGCTAACCTGGATAACTGT & CCTTGTGCAATGACTGGAGC \\
Exon 11 & (GC) GTCCATGCCACCATTCTTGG & GCCCTTTCTGCTTAATTCAG \\
\hline
\end{tabular}

(GC): 5' - CGCCCGCCGCGCCCCGCGCCCGTCCCGCCGCCCCCGCCCG - 3'. 
patients with $\mathrm{G} / \mathrm{G}$, two with Duarte/G, and four carriers of Wild type/G in nine Japanese families. DGGE analysis showed abnormal bands from exons 3 to 10 in the GALT gene (Figure 1), and also allowed distinguishing between wild-type and mutant alleles with homozygous V85N97fsdel38bp, R231H, and P325L mutations in exons 3, 8 and 10, respectively. Fourteen different mutations in 15 Japanese subjects were identified using DGGE analysis and direct sequencing (Table 3); the 14 mutations accounted for 22 of
23 mutant alleles, yielding a detection rate of $96 \%$. There was one allele with an unknown mutation in patient 8. We found only one mutation (W249R), using DGGE analysis and direct sequencing all 11 exons in patient 8 . The mutational spectrum included nine missense mutations (M142V, G179D, A199 T, R231H, W249R, N314D, P325L, R333Q, and R333W), a nonsense mutation (W249X), two splicing mutations (V85-N97fsdel38bp and IVS4nt ${ }^{+} 1$ ), and 2 deletions (L275fsdelT and Q317fsdelC). The two deletions of

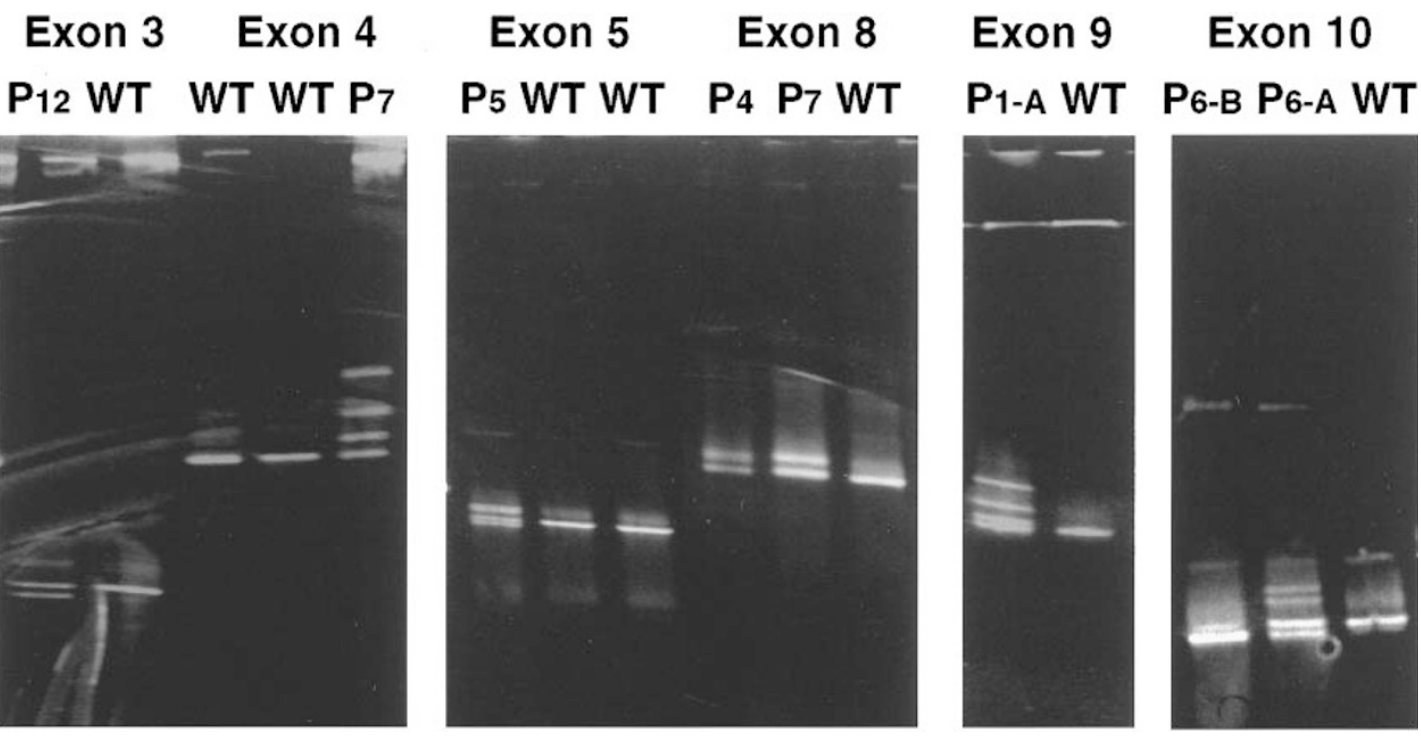

Figure $1 D G G E$ analysis of exons 3, 4, 5, 8, 9, and 10 in the GALT gene. $20 \mu$ l of amplified product was electrophoresed through a $20-80 \%$ denaturant and $6 \%$ acrylamide gel for $7 \mathrm{~h}$ at $61{ }^{\circ} \mathrm{C}$ and $160 \mathrm{~V}$. The four bands of exon 10 in patient $6 \mathrm{~A}$ indicated heterozygous P325L mutation based on results of direct sequencing of exon 10. A slightly faster single band of exon 10 in patient $6 B$ compared with wild-type controls indicated homozygous P325L mutations. The abnormal bands of exons 3, 4, 5, 8, and 9 indicated V85-N97fsdel38bp, IVS4nt+1, M142V, W249X, L275fsdelT, and P325L.P = patient number, WT = wild type.

Table 3 GALT mutations in Japanese patients with GALT deficiency

\begin{tabular}{|c|c|c|c|c|c|}
\hline Mutation & Position & Systematic name & $C p G$ & Conserved region & Number of alleles \\
\hline V85-N97fsdel38bp & Exon 3 & c. $290 \mathrm{~A}>\mathrm{G}$ & No & - & 4 \\
\hline IVS4nt +1 & Intron 4 & c. $377+1 \mathrm{~g}>\mathrm{t}$ & No & - & 1 \\
\hline M142V & Exon 5 & c. $424 \mathrm{~A}>\mathrm{G}$ & No & No & 1 \\
\hline G179D & Exon 6 & c. $536 \mathrm{G}>\mathrm{A}$ & No & Yes & 1 \\
\hline A199T & Exon 7 & c. $595 \mathrm{G}>\mathrm{A}$ & No & No & 1 \\
\hline $\mathrm{R} 231 \mathrm{H}$ & Exon 8 & c. $692 \mathrm{G}>\mathrm{A}$ & Yes & Yes & 2 \\
\hline W249R & Exon 8 & c. $745 \mathrm{~T}>\mathrm{C}$ & No & Yes & 1 \\
\hline W249X & Exon 8 & c. $747 \mathrm{G}>\mathrm{A}$ & No & Yes & 2 \\
\hline L275fsdelT & Exon 9 & c. 824delT & No & - & 1 \\
\hline N314D & Exon 10 & c. $940 \mathrm{~A}>\mathrm{G}$ & No & No & 2 \\
\hline Q317fsdelC & Exon 10 & c. 949 delC & No & - & 1 \\
\hline P325L & Exon 10 & c. $974 \mathrm{C}>\mathrm{T}$ & Yes & Yes & 3 \\
\hline R333Q & Exon 10 & c. $998 \mathrm{G}>\mathrm{A}$ & Yes & Yes & 1 \\
\hline R333W & Exon 10 & c. $997 \mathrm{C}>\mathrm{T}$ & Yes & Yes & 1 \\
\hline
\end{tabular}


L275fsdelT and Q317fsdelC resulted in in-frame nonsense codons at codons 279 and 358 .

\section{Relationship between N314D and Polymorphisms}

In family 6 , patient 6 A ( $19 \%$ of normal GALT activity in $\mathrm{RBC}$ ) had a genotype with N314D, g.1105G > C, g.1323G $>$ A, g.1391G $>$ A $\left(\right.$ SacI $\left.^{-}\right) /$P325L. Patient 6B (1\%) had a genotype with homozygous P325L. Their father $(22 \%)$ had a genotype similar to that of patient $6 \mathrm{~A}$, whilst their mother $(60 \%)$ was a heterogeneous carrier of P325L. Patient 6A and the father exhibited bands similar to those in Caucasians with Duarte variant on starch gel electrophoresis of GALT protein. ${ }^{21}$ In family 9 , patient $9(32 \%)$ had a genotype with N314D, g.1105G > C, g.1323G > A, g.1391G > A/ Q317fsdelC; his father (65\%) was a heterozygous carrier of Q317fsdelC, and his mother (85\%) was a heterozygous carrier of N314D, g.1105G $>C$, g.1323G > A, g.1391G > A. In families 6 and 9, the Duarte variant alleles were completely linked to N314D, g. $1105 \mathrm{G}>\mathrm{C}$, g.1323G $>\mathrm{A}$, and g.1391G $>$ A. The polymorphisms of g.1105G $>$ C, g.1323G $>$ A, g.1391G > A, and g.1721C > T (L218L) were also analysed in 13 families and two other normal phenotype individuals with Duarte variant. The four alleles of Duarte variant were completely linked to N314D, g. $1105 \mathrm{G}>\mathrm{C}$, g.1323G $>$ A, and g.1391G $>$ A, but not to g.1721C $>$ T, whilst 27 alleles of the wild-type and GALT deficiency did not link to g. $1105 \mathrm{G}>\mathrm{C}$, g.1323G > A, g.1391G > A, and g.1721C > T.

\section{Expression Analysis using the COS Cell System}

In order to determine whether the missense mutations identified in our patients caused galactosaemia, six missense mutations (M142V, G179D, A199T, W249R, $\mathrm{P} 325 \mathrm{~L}$, and R333Q) were examined for GALT activities using a COS cell expression system. The GALT activity of each mutant construct was established by calculating the efficiency of transfection into COS cells; this was done by determining GALT mRNA levels in transfected cells. GALT activities in all six mutations investigated were reduced, confirming that they were causal genes for galactosaemia (Table 4).

GALT mutations were classified into one of three groups based on in vitro GALT activity on COS cell expression analysis:

1) a severe genotype group with $W 249 R$ and G179D with $1.3-1.7 \%$ in vitro GALT activity as well as nonsense, splicing, and deletion;

2) an intermediate genotype group with $\mathrm{R} 231 \mathrm{H}$, $\mathrm{P} 325 \mathrm{~L}$, and M142V with $10-11 \%$ in vitro GALT activity; and

3) a mild genotype group with R333Q and A199T with 29 to $35 \%$ in vitro GALT activity.

There was no difference in RBC GALT activity between patients 3 and 7 with mutations of the severe genotype group in both alleles and patients 2 and $6 \mathrm{~B}$ with mutations of the intermediate genotype group; all values were $<2 \%$. Patients $1 \mathrm{~A}, 1 \mathrm{~B}$, and 4 exhibited

Table 4 GALT activity of missense mutations in COS cell expression analysis

\begin{tabular}{|c|c|c|c|c|}
\hline $\begin{array}{l}\text { Transfected DNA } \\
(p c D N A 3)\end{array}$ & $\begin{array}{l}\text { GALT activity } \\
\text { (unit/mg of protein) }\end{array}$ & $\begin{array}{l}m R N A \\
(\mathrm{cpm} / \mu \mathrm{g} \text { of total } R N A)\end{array}$ & $\begin{array}{l}\text { Corrected GALT activity } \\
\text { (unit/mg of protein) }\end{array}$ & $\begin{array}{l}\text { Percentage of } \\
\text { wild type GALT } \\
\text { activity }(\%)\end{array}$ \\
\hline \multicolumn{5}{|l|}{ Experiment 1} \\
\hline Wild type & 20.57 & 371 & 18.15 & 100 \\
\hline R333Q & 5.37 & 223 & 5.28 & 29 \\
\hline M142V & 3.73 & 247 & 2.07 & 11 \\
\hline P325L & 3.15 & 155 & 2.04 & 11 \\
\hline G179D & 2.66 & 316 & 0.30 & 1.7 \\
\hline W249R & 2.61 & 318 & 0.23 & 1.3 \\
\hline Mock & 2.42 & 35 & - & - \\
\hline \multicolumn{5}{|l|}{ Experiment 2} \\
\hline Wild Type & 16.56 & 748 & 14.52 & 100 \\
\hline A199T & 9.75 & 1106 & 5.07 & 35 \\
\hline $\mathrm{R} 231 \mathrm{H}$ & 3.46 & 711 & 1.56 & 10 \\
\hline Mock & 2.04 & 59 & - & - \\
\hline
\end{tabular}

${ }^{a}$ Corrected GALT activity of each mutated construct was determined by calculating the efficiency of transfection into COS cells; this was performed by determining GALT mRNA levels. 
compound heterozygous mutations in the severe and mild genotype groups, and exhibited greater than $2.5 \%$ GALT activities in RBCs or lymphoblasts (Table 1). They also exhibited a mild clinical phenotype with no ovarian failure or neurological deterioration, as described in Materials and Methods.

\section{Discussion}

Identification of mutations in Japanese subjects with GALT deficiency using the DGGE method and direct sequencing allowed detection of 14 different mutations in 22 of 23 GALT deficiency alleles, corresponding to a detection rate of $96 \%$. Greber-Platzer et $a l^{22}$ also reported a detection rate of $98 \%$ excluding exon 1 in an Austrian population using the DGGE method. This method is thus effective in detecting mutations in the GALT gene. Greber-Platzer et $a l^{22}$ could not detect the mutation in exon 1 due to high melting temperature despite several modifications of the DGGE procedure. In our Japanese patients, there were no mutations in exon 1 after DGGE and direct sequencing. We have not investigated and solved the limitation of the DGGE procedure for exon 1 . Therefore, our strategy for exon 1 was the direct sequence of exon 1 when we could not find both mutations by DGGE analysis. Among Japanese subjects, the most frequent of the 14 different mutations was V85-N97fsdel38bp, which was identified in only four of 23 alleles. The next most frequent mutation was $\mathrm{P} 325 \mathrm{~L}$, identified in three alleles. We found neither the Q188R mutation, which accounts for $>60 \%$ of mutations in Caucasians, ${ }^{6-8}$ nor the S135L mutation, which accounts for $40 \%$ of mutations in African-Americans. ${ }^{23}$ Thus, we could not find particularly prevalent mutations in Japanese subjects, and the causal genes for GALT deficiency in Japanese were heterogeneous. Though more than 100 mutations have been identified in Caucasians, only four mutations, N314D, P325L, R333W, and R333Q are common in both Caucasians and Japanese. The P325L R333W, and R333Q mutations occurred in the $\mathrm{CpG}$ dinucleotide, a mutation hot spot. The frequency of galactosaemia in Caucasians is 1 in 40000-60000, but is much lower in the Japanese, at 1 in 1000000 . This difference in frequency and the difference in spectrum of mutations suggest that Japanese and Caucasian mutations probably occurred independently. Thus, Japanese GALT mutations may have occurred after the divergence of
Caucasians and Asians. It is suspected that chromosomes with GALT deficiency, especially Q188R, produced favourable conditions for ancestral and/or modern Caucasians, and became high frequency. On the other hand, chromosomes with GALT deficiency did not have any merit and became the low frequency in the Japanese.

Genetic studies of Caucasians have shown that the N314D mutation is closely linked to the chromosome of the Duarte variant, and this substitution is considered to be the causal gene for the Duarte variant. ${ }^{11,12}$ The Duarte variant in the Japanese is also linked to the N314D mutation, and its frequency in the Japanese $2.0 \%,{ }^{24}$ similar to about $6 \%$ in Caucasians. ${ }^{11,25}$ However, it is still unclear whether the N314D mutation is a cause of GALT deficiency, since N314D mutant constructs in COS cells and yeast expression systems exhibited GALT activity equivalent to or exceeding that of the wild type. ${ }^{5,26}$ On the other hand, lymphoblasts with homozygous N314D mutation had reduced GALT enzyme activity due to protein instability. ${ }^{27}$ The association between the Duarte variant and DNA polymorphisms in Caucasians was reported first, g.1391G > A $\left(\mathrm{SacI}^{-}\right)$polymorphism, by Lin and Reichardt $^{13}$ second, g.1105G $>$ C, by Podskarbi et $a l^{28}$ and Greger-Platzer et $a l^{22}$ and third, g.1323G $>$ A, by Schuster et $a .^{29}$ Podskarbi et $a l^{28}$ and Greger-Platzer et $a l^{22}$ suspected that the g. $1391 \mathrm{G}>\mathrm{A}$ g.1105G $>$ C polymorphisms reduced GALT activity in Duarte variants. Duarte variants in the Japanese encoded g.1105G $>$ C, g.1323G > A, g.1391G > A polymorphisms, and the N314D mutation, as in Caucasians. We therefore suspect that the Duarte variant has occurred before racial divergence between Caucasians and Asians, and is an ancient mutation.

The correlation between the clinical phenotype and genotype of GALT deficiency is still unclear. Concerning the most prevalent Q188R mutation among Caucasians, patients with the homozygous Q188R mutation exhibited no GALT activity in RBCs and, clinically, exhibited ovarian failure and neurological deterioration with aging. ${ }^{6,8}$ The Q188R mutation exhibited $10 \%$ GALT activity in a COS cell expression system reported by Reichardt, ${ }^{30}$ a level similar to that observed in patients in our intermediate genotype group, whilst the Q188R mutation exhibited no in vitro GALT activity in the yeast expression system. ${ }^{31}$ The difference in in vitro GALT activity between COS cells and yeast expression systems was suspected to be due to the lack of GALT activity in yeasts. ${ }^{31}$ In this study, in vitro 
GALT activity in the intermediate and mild genotype groups was higher than the corresponding GALT activities in vivo. The major cause of high in vitro GALT activity is probably transient overexpression of mRNA transcribed from plasmid GALT cDNA with a strong promotor rather than steady-state expression of GALT proteins under in vivo physiological control.

Patients who were homozygous or compound heterozygous for the $\mathrm{P} 325 \mathrm{~L}, \mathrm{M} 142 \mathrm{~V}$, or R231H mutations in the intermediate genotype group $(10-11 \%$ in vitro GALT activity) exhibited less than 1\% GALT activity in RBCs and had the typical classic phenotype. Patients who were compound heterozygous for $\mathrm{R} 333 \mathrm{Q}$ or A199T in the mild genotype group (29-35\% in vitro GALT activity) exhibited 2.5-5\% GALT activity in RBCs or lymphoblasts. These patients are in a group with detectable GALT activity ranging from $0.1 \%$ to $5 \%$ of normal value similar to that reported by $\mathrm{Ng}$ et al ${ }^{8}$ and have a favourable clinical course. These findings indicate that GALT activities in COS cell expression system do not completely correspond with those in RBCs or lymphoblasts. However, in vitro GALT activities correlated with in vivo activities in RBCs or lymphoblasts. Therefore, the in vitro GALT activity system is useful for assessing the relative severity of GALT mutations and classifying GALT deficiencies. Our borderline between mild and classic phenotypes in GALT patients was $11-29 \%$ of in vitro GALT activity. We find mutations yielding between 11 and $29 \%$ in vitro GALT activity interesting, since these genotypes are related to non- or near non-detectable GALT activity in RBCs. Determination of genotypes and study of expression in patients after mass screening of newborns is useful for characterising the clinical and biochemical phenotypes and thus permits optimisation of therapy, determination of long-term prognosis, and providing intensive support for patients and their families.

\section{Acknowledgements}

We are grateful to Dr Won $\mathrm{G} \mathrm{Ng}$ of the Biochemical Genetics Laboratory at the Children's Hospital, Los Angeles, for analysing GALT activity in lymphoblasts. We also thank Dr T Oura of Tohoku University School of Medicine, Dr M Takayanagi of Chiba University School of Medicine, Dr E Kato of Fukui Saiseikai Hospital, Dr N Ozaki from Kishoin Hospital, and Dr M Yoshino of Kurume University School of Medicine for providing blood samples from patients with GALT deficiency. This study was supported in part by a grant from the Ministry of Education, Science and Culture of Japan.

\section{References}

1 Segal S, Berry GT: Disorders of galactose metabolism. In: Scriver CR, Beaudet AL, Sly WS, Valle D (eds). The Metabolic Basis of Inherited Disease, 7th edn. vol. 1. McGraw-Hill: New York, 1995, 967-1000.

2 Aoki K, Wada Y: Outcome of the patients detected by newborn screening in Japan. Acta Paediatr Jpn 1988; 30: 429-434.

3 Kaufman FR, Kogut MD, Donnell GN, Goebelsmann U, March C, Koch R: Hypergonadotrophic hypogonadism in female patients with galactosemia. $N$ Engl J Med 1981; 304: 994-998.

4 Waggoner DD, Buist NRM, Donnell GN: Long-term prognosis in galactosaemia: results of a survey of 350 cases. J Inher Metab Dis 1990; 13: 802-818.

5 Reichardt JKV, Woo SLC: Molecular basis of galactosemia: mutations and polymorphisms in the gene encoding human galactose-1-phosphate uridylyltransferase. Proc Natl Acad Sci USA 1991; 88: 2633-2637.

6 Elsas LJ, Fridovich-Keil JL, Leslie ND: Galactosemia: a molecular approach to the enigma. Int Pediatr 1993; 8: 101-109.

7 Kaufman FR, Reichardt JKV, Ng WG et al: Correlation of cognitive, neurologic, and ovarian outcome with the Q188R mutation of the galactose-1-phosphate uridyltransferase gene. J Pediatr 1994; 125: 225-227.

$8 \mathrm{Ng}$ WG, Xu Y-K, Kaufman FR et al: Biochemical and molecular studies of 132 patients with galactosemia. Hum Genet 1994; 94: 359-363.

9 Sommer M, Gathof BS, Podskarbi T, Giugliani R, Kleinlein B, Shin YS: Mutations in the galactose-1-phosphate uridyltransferase gene of two families with mild galactosemia variants. $J$ Inher Metab Dis 1995; 18: 567-576.

10 Shin YS, Gathof BS, Podskarbi T, Sommer M, Giugliani R, Gresser U: Three missense mutations in the galactose1-phosphate uridyltransferase gene of three families with mild galactosemia. Eur J Pediatr 1996; 155: 393-397.

11 Elsas LJ, Dembure PP, Langley S, Paulk EM, Hjelm LN, Fridovich-Keil J: A common mutation associated with the Duarte galactosemia allele. Am J Hum Genet 1994; 54: 1030-1036.

12 Lin H-C, Kirby LT, Ng WG, Reichardt JKV: On the molecular nature of the Duarte variant of galactose1-phosphate uridyl transferase (GALT). Hum Genet 1994; 93: $167-169$.

13 Lin H-C, Reichardt JKV: Linkage disequilibrium between a $S a c$ I restriction fragment length polymorphism and two galactosemia mutations. Hum Genet 1995; 95: 353-355.

14 Langley SD, Lai K, Dembure PP, Hjelm LN, Elsas LJ: Molecular basis for Duarte and Los Angeles variant galactosemia. Am J Hum Genet 1997; 60: 366-372.

15 Ashino J, Okano Y, Suyama I et al : Molecular characterization of galactosemia (type 1) mutations in Japanese. Hum Mutat 1995; 6: 36-43.

16 Oura T, Miyabayashi S, Iinuma K, Narisawa K, Konno T, Okano Y: Follow up study of the galactosemia type 1 sisters. Bull Spec Formul 1997; 33: 33-35. 
17 Ozaki N: Follow up study to puberty of the galactosemia type 1 girl. Bull Spec Formul 1997; 33: 36-37.

18 Myers RM, Fischer SG, Lerman LS, Maniatis T: Nearly all single base substitutions in DNA fragments joined to a GC-clamp can be detected by denaturing gradient gel electrophoresis. Nucleic Acids Res 1985; 13: 3131-3145.

19 Reichardt JKV, Berg P: Cloning and characterization of a cDNA encoding human galactose-1-phosphate uridyl transferase. Mol Biol Med 1988; 5: 107-122.

20 Okano Y, Hase Y, Shintaku H et al: Molecular characterization of phenylketonuric mutations in Japanese by analysis of phenylalanine hydroxylase mRNA from lymphoblasts. Hum Mol Genet 1994; 3: 659-660.

21 Aramaki S, Watari H, Mtsuura N: A sibling case with galactosemia type 1 and Duarte variant. Bull Spec Formul 1989; 19: 10-13.

22 Greber-Platzer S, Guldberg P, Scheibenreiter S et al: Molecular heterogeneity of classical and Duarte galactosemia: Mutation analysis by denaturing gradient gel electrophoresis. Hum Mutat 1997; 10: 49-57.

23 Lai K, Langley SD, Singh RH, Dembure PP, Hjelm LN, Elsas II LJ: A prevalent mutation for galactosemia among black Americans. J Pediatr 1996; 128: 89-95.

24 Ichiba Y: The variant of galactosemia. Jpn J Pediatr 1989; 42: $579-582$

25 Sparkes MC, Crist M, Sparkes RS: Improved technique for electrophoresis of human galactose-1-P uridyltransferase (EC2.7.7.12). Hum Genet 1977; 40: 93-97.
26 Fridovich-Keil JL, Quimby BB, Wells L, Mazur LA, Elsevier JP: Characterization of the N314D allele of human galactose-1-phosphate uridyltransferase using a yeast expression system. Biochem Mol Med 1995; 56: $121-130$.

27 Lai K, Langley SD, Dembure PP, Hjelm LN, Elsas II LJ: Duarte allele impairs biostability of galactose-1-phosphate uridyltransferase in human lymphoblasts. Hum Mutat 1998; 11: 28-38.

28 Podskarbi T, Kohlmetz T, Gathof BS et al: Molecular characterization of Duarte- 1 and Duarte-2 variants of galactose-1-phosphate uridyltransferase. J Inher Metab Dis 1996; 19: 638-644.

29 Schuster V, Podskarbi T, Ottensmeier H, Haubner M, Shin YS: Simultaneous occurrence of various mutations and polymorphisms in cis and intrans of the galactose1-phosphate uridyltransferase gene in a Turkish family with classical galactosemia. J Mol Med 1998; 76: 715-719.

30 Reichardt JKV, Packman S, Woo SLC: Molecular characterization of two galactosemia mutations: correlation of mutations with highly conserved domains in galactose1-phosphate uridyl transferase. Am J Hum Genet 1991; 49: 860-867.

31 Fridovich-Keil JL, Jinks-Robertson S: A yeast expression system for human galactose-1-phosphate uridyltransferase. Proc Natl Acad Sci USA 1993; 90: 398-402. 